\title{
Nonocclusive Mesenteric Ischemia in a Patient on Maintenance Hemodialys is
}

\author{
Sang Youb Han, M.D., Young Joo Kwon, M.D., Jin Ho Shin M.D. \\ Heui Jung Pyo, M.D., Ae Ree Kim, M.D.* \\ Div is ion of Nephrology, Department of Inte rnal Medicine, Department of \\ Anatomic Pathology*, College of Medicine, Korea University, Seoul, Korea
}

\begin{abstract}
Nonocclusive mesenteric ischemia(NOMI) is known to occupy about $25 \%$ to $60 \%$ of intestinal infarction. NOMI has been reported to be responsible for $9 \%$ of the deaths in the dialysis population and the postulated causes of NOMI include intradialytic hypotension, atherosclerosis and medications, such as diuretics, digitalis and vasopressors. Clinical manifestations, such as fever, diarrhea and le ukocytosis, are nonspecific, which makes early diagnosis of NOMIvery difficult. Case: A 66-year-old woman on maintenance hemodialysis for 5 years was admitted with syncope, abdominal pain and chilly sensation. Since 7 days prior to admission, blood pressure on the supine position during hemodialys is had frequently fallen to $80 / 50 \mathrm{~mm} \mathrm{Hg}$. Four days later, she complained of progressive abdominal pain. Rebound tenderness

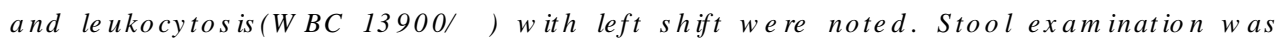
positive for occult blood. Abdominal CT scan showed a distended gall bladder with sludge. Under the impression of acalculous cholecystitis, she was operated on. $S$ urg ical and pathologic finding sof colon colon were compatible with NOMI. Because of recurrent intradialytic hypotension, we started midodrine $2.5 \mathrm{mg}$ just before hemodialys is and increased the dose up to $7.5 \mathrm{mg}$. After midodrine the rapy, blood pressure during dialysis became stable and the symptoms associated with hypotension did not recur. Conclusion: As NOMI may occur within several hours or days after an intradialytic hypotensive episode, abdominal pain should be carefully observed and NOMI should be considered as a differential diagnosis. In addition, we suggest that midodrine be considered to prevent intradialytic hypotensive episodes.
\end{abstract}

Key wo rd : Nonocclusive mesenteric ischemia(NOMI), dialysis, midodrine

\section{INTRODUCT ION}

Nonocclusive mesenteric ischemia(NOMI) was reported in a heart failure patient by Ende in $1958^{1)}$. In dialys is patients, Dahlberg et al. ${ }^{2}$ reported 6 patients with acute mesenteric ischemia, and 3 of them were NOMI NOMI is the cause in at least $20 \%$ to $30 \%$ of cases of acute mesenteric ischemia ${ }^{3}$, and the mortality rates of NOMI were reported from $71 \%$ to $100 \%(4)$. Diamond et

Address reprint requests to : Young Joo Kwon, M.D., Div. of Nephrology, Dept. of Internal Medicine, Korea University Guro Hospital, \#80 Guro-Dong Guro-Gu Seoul, South Korea 152-050 al.' reported that NOMI was the cause of mortality in $9 \%(5 / 56)$ of the deaths in the dialys is population. So, early recognition and prompt management is necessary to improve survival.

We describe NOMI in a patient with hypotensive episodes in dialysis therapy who was admitted with abdominal pain and who undertook colectomy. Hypotensive episodes decreased and related symptoms were improved after midodrine therapy.

\section{CASE}

A 66-year-old woman on maintenance hemodialys is for 5 years was admitted with syncope, abdominal pain 
and chilly sensation. She had been also diagnosed as having microvascular angina 3 years prior to admission. Hemodialysis was being done 3 times per week : her dry body weight was $46 \mathrm{~kg}$ and the interdialytic weight changes were about $3 \mathrm{~kg}$. Her interdialytic, systolic and diastolic pressures had been 100 to $140 \mathrm{mmHg}$ and 90 to $100 \mathrm{mmHg}$ on the supine position, respectively. During hemodialysis, systolic pressures had been above $100 \mathrm{mmHg}$ on supine position. However, interdialytic and intradialytic blood pressures had showed a tendency to decrease for several months prior to admission. So, she had not taken antihypertensive medication to prevent intradialytic hypotension.

Since 7 days prior to admission, blood pressure on the supine position during hemodialysis had frequently fallen to $80 / 50 \mathrm{mmHg}$. On admission, the blood pressure on the supine position was $80 / 50 \mathrm{mmHg}$, body temperature $38.8^{\circ} \mathrm{C}$, heart rate 104 per minute and respiratory rate 26 per minute. Abdominal examination showed mild abdominal tenderness without rebound tenderness.

Laboratory data were as follows: leukocyte count $5200 / \mathrm{mm}^{3}$ with normal differential count. hemoglobin 12.8 $\mathrm{g} / \mathrm{dL}$, platelet count $112000 / \mu \mathrm{L}$, Bun $60 \mathrm{mg} / \mathrm{dL}$, serum creatinine $7.3 \mathrm{mg} / \mathrm{dL}$, calcium $9.8 \mathrm{mg} / \mathrm{dL}$, phosphorus 7.3 $\mathrm{mg} / \mathrm{dL}$, AST $63 \mathrm{IU} / \mathrm{L}$, ALT $64 \mathrm{IU} / \mathrm{L}$, alkaline phosphatase $89 \mathrm{IU} / \mathrm{L}, \mathrm{Y}$ - glutamyl transferase $55 \mathrm{IU} / \mathrm{L}$, bilirubin $0.54 \mathrm{mg}$ $/ \mathrm{dL}$, total prote in $8.6 \mathrm{~g} / \mathrm{dL}$, albumin $5.7 \mathrm{~g} / \mathrm{dL}$, amylase 480 IU/L(normal, 60- 180), lipase $13 \mathrm{IU} / \mathrm{L}$ (normal, 30- 190), PT 11.6 second(INR $0.98 \mathrm{sec}$ ) and aPTT 40.1 second(control $30 \mathrm{sec})$. Simple abdominal $\mathrm{x}$-ray and abdominal ultrasound did not reveal any abnormal findings. 2-D echocardiography showed diffuse left ventricular dysfunction with slightly decreased ejection fraction.

Four days later, she complained of progressive abdominal pain, and rebound tenderness and leukocytos is (leukocyte count 13900/mm ) with left shift were noted. Stool examination was positive for occult blood. Abdominal CT scan showed a distended gall bladder with sludge. Under the impression of acalculous cholesystitis, she was operated on. On operation, ischemic necrosis at the sigmoid colon and mesocolon in addition to acalculous cholesystitis were found, and Hartman's operation and cholecystectomy were undertaken. Pathologic findings of the colon were compatible with NOM(Fig. 1).

After that, systolic blood pressures rose to 80 to 100 $\mathrm{mmHg}$, but intradialytic hypotension $(60 / 30 \mathrm{mmHg})$ occurred recurrently. We started midodrine $2.5 \mathrm{mg}$ just before hemodialysis and increased the dose up to $7.5 \mathrm{mg}$. After midodrine therapy, the blood pressure during dialysis became stable. Although hypotensive episodes occurred, the degree of hypotension was mild and the symptoms associated with hypotension did not occur(Fig. 2).

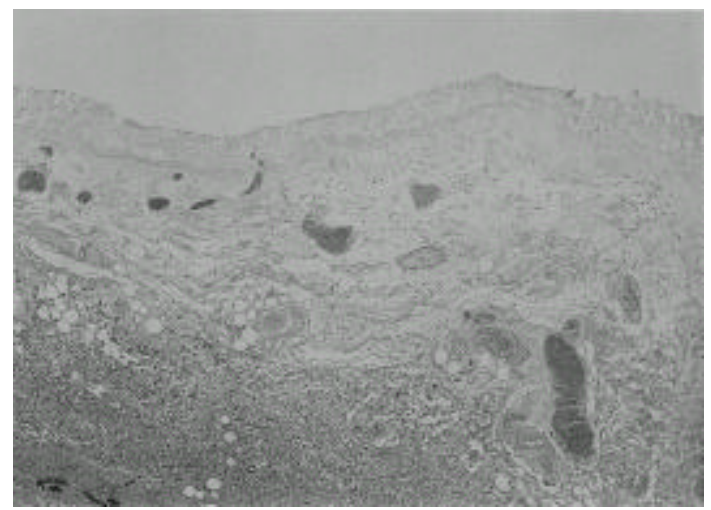

Fig. 1. Pathology of resected colon.

The wall of the colon shows superficial sloghing of the epithe lium with preservation of the architecture. There are edema, congestion and an inflammatory exudate in the submucosa.(Hematoxylin and Eosin, *40)

\section{DIS CUS S ION}

In chronic renal failure, peptic ulcer and colonic dysfunction are the most common gastrointestinal manifestations. They may be complicated by perforation, bleeding, constipation and colonic pseudoobstruction. However, ischemic bowel disease is less frequently recognized in the dialysis population ${ }^{4}$. As a cause of acute mesenteric ischemia, NOMI has been emerging importantly. Bender et al. $^{6)}$ reported that 11 of 12 patients with acute abdomen undergoing hemodialys is were diagnosed as NOMI Therefore, they insisted that NOMI be the most common cause of acute abdomen in dialyzed patients and should be the most probable diagnosis until proven otherwise.

Patients with ESRD have several risk factors for bowel infarction, which include advanced atherosclerosis, low cardiac output states, several medications and intradialytic hypotensive episodes.

Low cardiac output states such as heart failure, 


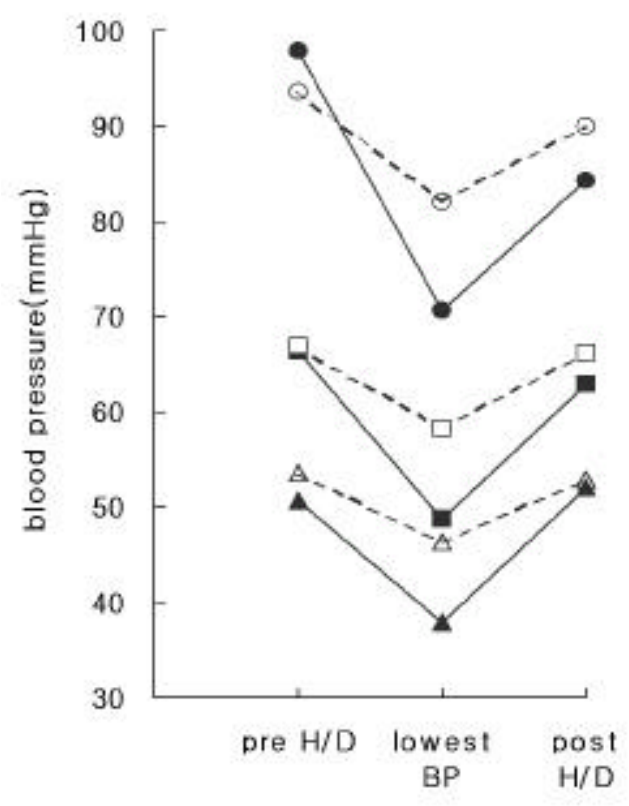

Fig. 2. Blood pressure(BP) without and with midodrine. Each blood pressure was recorded for consecutive hemodialysis sessions before and after midodrine therapy. Each point is a mean value of 14 recorded values(hard line : before midodrine therapy, dot line : after midodrine therapy, $\bigcirc$ : systolic BP, $\square$ :mean arterial pressure, $\triangle$ : diastolic BP). There were significant differences between before and after midodrine therapy in the lowest blood pressure during hemodialysis by Student's t-test. $(\bigcirc: \mathrm{p}=0.012, \square: \mathrm{p}=0.007, \triangle$ : $\mathrm{p}=0.047$ )

myocardial infarction, arrhythmia, sepsis and hypovolemia, may decrease splanchnic blood flow and cause vasoconstriction by excessive sympathetic activity that will eventually lead to NOMi'. Mesenteric vasospasm may represent a homeostatic mechanism to maintain cardiac and cerebral perfusion. Such splanchnic vasoconstriction is potentiated by a number of vasoactive agents. Reduced blood flow from vasoconstriction induces inadequate intestinal tissue oxygenation and results in vulnerability to tissue injury as well as reperfusion injury by oxygen radicals ${ }^{8}$.

Several medications such as diuretics ${ }^{9)}, \beta$-blockers ${ }^{10)}$ and digoxin $^{11)}$ have been associated with NOML
Symptomatic intradialytic hypotension has been described to occur in as many as $20 \%$ to $50 \%$ of patients ${ }^{3}$. This problem has been ascribed to multiple factors including excessively rapid ultrafiltration rate ${ }^{12)}$, autonomic dysfunction ${ }^{13)}$, disturbance in cardiac function and vascular responsiveness ${ }^{14)}$ and paradoxical withdrawal of sympathetic activity ${ }^{15}$.

In our case, the repetitive intradialytic hypotensive episodes may be the cause of NOML. The cause of hypotensive episodes was not clear, but uremia-induced autonomic dysfunction might be considered. Head-up tilting test may be helpful in making a diagnosis of autonomic dysfuction.

Because symptoms and signs of NOMI are nonspecific, the diagnosis of this entity is very difficult. Charra et $\mathrm{al}^{16)}$ reported the clinical features of 13 bowel necrosis episodes in hemodialys is patients. All of them complained of abdominal pain. Although fever, ileus, diarrhea and leukocytosis were found, they were not constant manifestations. In contrast to Charra's report, Howard et al. ${ }^{17)}$ reported the absence of abdominal pain in 20 to $25 \%$ of cases with NOMI Our case also showed nonspecific manifestations such as abdominal pain, fever and leukocytos is.

Splanchnic vasospasm, which may develop in hours or days after the initial insult, results in a delayed appearance of the disorder? ${ }^{7)}$. Therefore, the diagnosis of this condition should be considered whenever dialys is patients with risk factors complain of severe and abrupt abdominal discomfort within several hours or several days after intradialytic hypotensive episodes. Four days after nonspecific abdominal pain, our case was diagnosed as NOMI by surgical and pathological findings.

After colectomy, this patient continued to show recurrent intradialytic hypotensive episodes. For the prevention of these episodes, a variety of maneuvers, including sodium modeling and cooling of the dialysate, have been used with no success before the trial of midodrine therapy.

Midodrine is an oral agent with selective a -adrenergic agonist activity that has been used successfully in the treatment of orthostatic hypotension secondary to autonomic dysfunction ${ }^{18)}$. The efficacy of midodrine therapy in patients with intradialytic hypotension was reported by Blowey et al. ${ }^{19)}$. Midodrine is a prodrug that is rapidly and almost completely absorbed from the gastrointestinal tract after oral 
administration. The peak plasma levels of midodrine and its active metabolites, de-glymidodrine, were observed 60 and 90 minutes after the oral dose, respectively. De-glymidodrine was effectively removed by hemodialys is $\left(\mathrm{t}_{1 / 2}: 10 \mathrm{hrs}\right.$ without dialys is, $1.4 \mathrm{hr}$ with dialysis $)^{19)}$. The effect of midodrine to increase blood pressure comes from its constrictive effect on the arterioles and venous capacitant vessels. In this way, it prevents venous blood pooling and augments venous return which will subsequently increase cardiac output ${ }^{20)}$. Generally, midodrine appears to be well tolerated. It has minimal cardiac and central nervous system effects by virtue of is $a-1$ receptor specificity and its inability to cross the blood-brain barrier, respectively. Adverse effects such as piloerctor reactions, scalp pruritus, urinary urgency and headache were observed but they were usually mild ${ }^{20)}$

In our case, midodrine has decreased intradialytic hypotensive episodes without adverse effects for six months. The blood pressure became more stable after a trial of midodrine than before(Figure 2). We compared the frequency of intradialytic hypotensive episode between before and after a trial of midodrine when ultrafiltration volume was below $3 \mathrm{~kg}$. The frequencies of ultrafiltration volume under $3 \mathrm{~kg}$ were 7 and 11 of each 14 sessions before and after midodrine therapy. Intradialytic hypotensive episodes occurred in 6 of 7 sessions before midodrine therapy and 4 of 11 sessions after midodrine therapy, respectively $(\mathrm{p}=0.04)$. Also, the degree of intradialytic hypotension was changed. Intradialytic hypotension, before midodrine therapy, had fallen to $50 \mathrm{mmHg}$ of systolic pressures, but the systolic pressures had fallen only to $80 \mathrm{mmHg}$ after midodrine the rapy.

In conclusion, NOMI should be included in differential diagnosis when patients on maintenance dialys is present abdominal pain after intradialytic hypotension. Also, we suggest that midodrine be considered for the treatment of intradialytic hypotension of unknown origin or unresponsiveness to other trials.

\section{REFERENCES}

1. Ende $\mathrm{N}$ : Infarction of the bowel in cardiac failure. $N$ Eng J Med 1958,258:879-881

2. Dahlberg PJ, Kis ken WA, Newcomer KL, Yutuc WR : Mesenteric ischemia in chronic diabsis patients. Am J Nephrol 1985;5:327-332

3. Sherman RA : The pathophysiologic basis for hemo- diabs sis related hypotension. Semin Dial 1988; 1:136-141

4. Sachs SM, Horton JH, Schwartz SI : Acute mesenteric ischemia. Surgery 1982.92: 646-653

5. Diamond SM, Emmett M, Henrich WL : Bowel infartion as a cause of death in diabsis patients. JAMA 1986; 2562545-2547

6. Bender JS, Ratner LE, Magnuson TH, Zenilman ME : Acute abdomen in the hemodialysis patient population Surgery 1995;117.494-7

7. Aldrette JS, Han SY, Laws HL, Kirklin JW, Alabama B : Intestinal infarction complicating low cardiac ouput states. Surg Gynecol Obstet 1977; 144;371-375

8. Granger DN, Hollwart ME, Parks DA. Ischemicreperfusion injury: Role of oxygen-derived free radicals. Acta Physiol Scand(Suppl) 1986;548.47-64

9. Sharefkin JB, Silen W : Diurectic agents inciting factor in nonocclusive mesenteric infarction? JAMA 1974,229: 145 1- 1453

10. Williams LF. Mesenteric Ischemia : Surg Clin North Am 1988;68:33 1-353

11. Kim EH, Gewertz BL : Chronic digitalis administration alters mesenteric vascular reactivity. J Vasc Surg 1987; 5:382-389

12. Henrich WL: Hemodynamic instability duning hemodiabsis. Kidney Int 1986;30: 605-6D

13. Ewing DJ, Winney R : Autonomic function in patients with chronic renal failure on intermittent hemodialysis. Nephron 1975;15:424-429

14. Noris M, Benigni A, Boccardo P, Aiello S, Gaspari F, Tedeschini M, Figleuzzi M, Remuzzi G. : Enhanced nitric oxide synthesis in uremia: Implications for platelet dysfunction and diabsis hypotension. Kidney Int 1993;44.445-450

15. Converse RL, Jacobsen TN, Jost CMT, Toto RD, Grayburn PA, Victor RG : Paradoxical withdrawal of reflex vasoconstriction as a cause of hemodialysis induced hypotension. J Clin Invest 1992;90:1657-1665

16. Charra B, Cuche J, Ruffet M, Terrat JC, Beurlet J, Labrosse H, Vanel T, Calemard E, Chazot C, Vovan C, Jean G, Laurent G : Segmental necrosis of ascending colon in haemodialysis patients. Nephrol Dial Transplant 1995; 102281-2285

17. Howard TJ, Plaskon LA, Wiebke EA, Wilcox MG : Nonocclusive mesenteric remains a diagnostic dilemma. Am J Surg 1996;171:405-408

18. Fouad-Tarazi M, Okabe M, Goren H : Aphasympathomimetic treatment of autonomic insufficiency with orthostatic hypotension. Am J Med 1995;99.604-610

19. Blowey DL, Balfe JW, Gupta I, Gajaria MM, Koren G : Midodrine efficacy and phamacokinetics in a patient with recurrent intradialytic hypotension. Am J Kindey dis 1996;28:132- 136

20. Jankovic J, Gilden JL, Hinder BC, Kaufmann H, Brown DC, Coghlan CH, Rubin M, Fouad-Tarazi FM : Neurogenic orthostatic hypotension: A double-blind, placebo controlled study with midodrine. Am J Med 1993;95:38-48 